\title{
Soil microorganisms control plant ectoparasitic nematodes in natural coastal foredunes
}

\author{
Anna M. Piśkiewicz • Henk Duyts • Matty P. Berg • \\ Sofia R. Costa $\cdot$ Wim H. van der Putten
}

Received: 21 June 2006 / Accepted: 24 January 2007 / Published online: 8 March 2007

(C) Springer-Verlag 2007

\begin{abstract}
Belowground herbivores can exert important controls on the composition of natural plant communities. Until now, relatively few studies have investigated which factors may control the abundance of belowground herbivores. In Dutch coastal foredunes, the root-feeding nematode Tylenchorhynchus ventralis is capable of reducing the performance of the dominant grass Ammophila arenaria (Marram grass). However, field surveys show that populations of this nematode usually are controlled to nondamaging densities, but the control mechanism is unknown. In the present study, we first established that $T$. ventralis populations are top-down controlled by soil biota. Then, selective removal of soil fauna suggested that soil
\end{abstract}

Communicated by Wolfgang Weiser.

A. M. Piśkiewicz $(\bowtie) \cdot H$. Duyts $\cdot$ W. H. van der Putten Department of Multitrophic Interactions,

Centre for Terrestrial Ecology,

Netherlands Institute of Ecology , Boterhoeksestraat 48,

P.O. Box 40, 6666 ZG Heteren, The Netherlands

e-mail: a.piskiewicz@nioo.knaw.nl

\section{P. Berg}

Institute of Ecological Science,

Department of Animal Ecology,

Vrije Universiteit Amsterdam, De Boelelaan 1085,

1081 HV Amsterdam, The Netherlands

\section{S. R. Costa}

Nematode Interactions Unit,

Rothamsted Research, Harpenden,

Hertfordshire AL5 2JQ, UK

W. H. van der Putten

Laboratory of Nematology,

Wageningen University,

Binnenhaven 5, 6709 PD Wageningen,

The Netherlands microorganisms play an important role in controlling T. ventralis. This result was confirmed by an experiment where selective inoculation of microarthropods, nematodes and microbes together with $T$. ventralis into sterilized dune soil resulted in nematode control when microbes were present. Adding nematodes had some effect, whereas microarthropods did not have a significant effect on $T$. ventralis. Our results have important implications for the appreciation of herbivore controls in natural soils. Soil food web models assume that herbivorous nematodes are controlled by predaceous invertebrates, whereas many biological control studies focus on managing nematode abundance by soil microorganisms. We propose that soil microorganisms play a more important role than do carnivorous soil invertebrates in the top-down control of herbivorous ectoparasitic nematodes in natural ecosystems. This is opposite to many studies on factors controlling rootfeeding insects, which are supposed to be controlled by carnivorous invertebrates, parasitoids, or entomopathogenic nematodes. Our conclusion is that the ectoparasitic nematode $T$. ventralis is potentially able to limit productivity of the dune grass $A$. arenaria but that soil organisms, mostly microorganisms, usually prevent the development of growth-reducing population densities.

Keywords Root herbivory · Top-down control · Multitrophic interactions $\cdot$ Ammophila arenaria . Tylenchorhynchus ventralis

\section{Introduction}

Root herbivores play an important role in shaping the composition of natural plant communities (Brown and 
Gange 1990). Nematodes and insects represent the vast majority of the belowground herbivores (Brown and Gange 1990; Stanton 1988). Nematodes are more abundant than soil insects, and in some grassland ecosystems, nematodes are the dominant herbivores (Ingham and Detling 1986). Root-feeding nematodes have been estimated to take up as much as one quarter of the net primary production of grassland vegetation (Stanton 1988), and they affect plant quality (Davis et al. 1994; Troelstra et al. 2001), plant diversity, and vegetation succession (de Deyn et al. 2003). Root-feeding nematodes can also indirectly affect plant performance by their influence on bottom-up and top-down control of aboveground invertebrate herbivores (Bezemer et al. 2005). However, in spite of the increasing knowledge on the significant role of belowground herbivores in the control of plant abundance and plant community composition, relatively few studies have investigated which factors control the abundance of the belowground herbivores in natural ecosystems (Strong et al. 1996, 1999).

Herbivore abundance can be influenced by natural enemies (top-down), by the host plant (bottom-up), and by competition with other herbivores (horizontal control). In (semi) natural ecosystems, most studies on the control of root-feeding nematodes have focused on plant quality (Yeates 1987), interspecific competition (Brinkman et al. 2004, 2005), plant community composition (de Deyn et al. 2004), plant succession and soil conditions (Verschoor et al. 2002), and mycorrhizal fungi (de la Peña et al. 2006). Soil food web models assume root-feeding nematodes to be controlled by carnivorous nematodes and microarthropods (Hunt et al. 1987; Neutel et al. 2002). However, most biological control studies in agricultural systems focus on managing nematode abundance by parasitic soil microorganisms (Kerry 2000; Sikora 1992) or mycorrhizal fungi (Hol and Cook 2005), suggesting that root-feeding nematodes are mainly controlled by microorganisms. Therefore, previous studies show little agreement and do not clearly predict how root-feeding nematodes will be controlled in natural ecosystems.

Empirical data for top-down mechanisms are rare for terrestrial ecosystems relative to the many studies in aquatic systems (Walker and Jones 2001). In general, trophic cascades have been argued to be less common on land than in water (Polis and Strong 1996). Nevertheless, there is empirical evidence supporting the existence of trophic cascades in terrestrial plantpredator-prey systems (Schmitz et al. 2004). Tritrophic systems of plants, aboveground insect herbivores, and their natural aboveground enemies are the best-studied terrestrial examples of top-down and bottom-up herbivore controls (Carson and Root 1999; Rosenheim 1998). Below ground, tritrophic interactions may not essentially differ from what is known above ground (Bezemer and van Dam 2005), although rates of dispersal of organisms and chemical compounds will be lower than is mostly the case above ground (Rasmann et al. 2005; van der Putten 2003). Therefore, the challenge is, similar to that above ground (Schmitz et al. 2004), to assess what controls the abundance of root herbivores. This knowledge will enhance our understanding of belowground multitrophic interactions and their influences on plant performance and plant community composition.

In the present study, the role of microarthropods, nematodes, and microorganisms in controlling the abundance of the root-feeding nematode Tylenchorhynchus ventralis (Loof 1963) Fortuner and Luc (synonym Telotylenchus ventralis) was experimentally compared. This nematode is a polyphagous ectoparasite, which means that it is a quite generalistic root feeder that penetrates outer cortical cells with its stylet to collect and ingest cell contents (Yeates et al. 1993). $T$. ventralis is a root parasite of the dominant coastal foredune grass Ammophila arenaria (Marram grass). In field soil, $T$. ventralis reaches densities that are 80 times lower than achieved when inoculated into sterilized dune soil (de Rooij van der Goes 1995). Whereas $T$. ventralis can strongly reduce growth of $A$. arenaria in sterilized soil, field densities in nonsterilized soil are too low to directly influence plant performance (de Rooij van der Goes 1995). The roots of $A$. arenaria are parasitized by an array of herbivorous nematodes ranging from ectoparasites to sedentary endoparasites (de Rooij van der Goes et al. 1995). The control mechanisms of root herbivorous nematodes in dunes appear to highly depend on the feeding type of the nematode, and even on the species of nematode. Whereas the sedentary root knot nematode Meloidogyne maritima (Jepson 1987) Karssen, van Aelst and Cook is controlled by competition (Brinkman et al. 2005), the sedentary cyst nematode Heterodera arenaria (Cooper 1955) Robinson, Stone, Hooper and Rowe appears to be controlled by bottom-up processes (van der Stoel et al. 2006). The migratory endoparasitic root lesion nematode Pratylenchus penetrans (Cobb 1917) is controlled by arbuscular mycorrhizal fungi (de la Peña et al. 2006). Thus far, the factors that control the ectoparasitic nematode $T$. ventralis associated with $A$. arenaria are unknown.

Previous studies showed bottom-up control of $A$. arenaria to occur only when the plants were severely growth reduced (de Rooij van der Goes et al. 1995). Alternatively, competition with cyst and root lesion 
nematodes is a potential factor controlling ectoparasitic nematodes (Eisenback 1993). However, endoparasitic nematodes did not control abundance of $T$. ventralis (Brinkman et al. 2004). In the present study, the top-down factors that may be involved in the control of $T$. ventralis populations were investigated in order to determine how belowground trophic interactions might influence plant performance and vegetation composition.

To assess the top-down control of $T$. ventralis, three experiments were performed. The aim of experiment 1 was to elucidate the potential top-down control of $T$. ventralis by the dune soil community. In experiment 2 , the particular role of microorganisms was investigated by selective elimination of soil fauna (nematodes and microarthropods). In experiment 3 , the hypothesis that emerged from experiment 2 , that soil microorganisms are the main cause of top-down control of $T$. ventralis, was tested. Here, we applied Koch's postulates by collecting microorganisms, nematodes, and microarthropods from dune soil and adding them to sterilized soil inoculated with $T$. ventralis. New evidence that topdown control by soil microorganisms is the most important factor controlling the abundance of ectoparasitic nematodes in dune soil is presented and discussed.

\section{Materials and methods}

Soil

In summer 2003, soil samples were collected from mobile and stable foredunes at Voorne, The Netherlands (Latitude $51^{\circ} 55^{\prime} \mathrm{N}$ to Longitude $04^{\circ} 05^{\prime} \mathrm{E}$ ). The samples were collected along six transects parallel to the beach and $50 \mathrm{~m}$ apart. At each sampling station in the mobile and stable dune, $60 \mathrm{~kg}$ of soil was collected from the youngest root zone of $A$. arenaria. The soil was sieved $(0.5-\mathrm{cm}$ mesh size) to remove plant parts and debris and stored in plastic bags at $4{ }^{\circ} \mathrm{C}$ until used (van der Stoel et al. 2002).

\section{Plants}

Seeds of $A$. arenaria were collected from the same foredune area and stored dry until used. In order to obtain seedlings, the seeds were germinated for 2 weeks on moist glass beads in a climate room at a 16/ $8 \mathrm{~h} \mathrm{light/dark}$ regime at a temperature of $25 / 15^{\circ} \mathrm{C}$, respectively. When the first leaf was $2-3 \mathrm{~cm}$ long, the seedlings were transplanted to $1.5-1$ plastic pots filled with $1,500 \mathrm{~g}$ of dune soil. In each pot, four seedlings of
A. arenaria were planted, and the soil surface was covered with aluminum foil to protect the soil from desiccation. The soil moisture was adjusted to $10 \% \mathrm{w} / \mathrm{w}$ and maintained at this level throughout the experiment by weighing the pots twice a week and resetting their initial weight using demineralized water. Once a week, full-strength Hoagland nutrient solution was added at a weekly rate of $12.5 \mathrm{ml} \mathrm{pot}^{-1}$ for the first 3 weeks and then $25 \mathrm{ml} \mathrm{pot}^{-1}$, subsequently (Brinkman et al. 2004). This nutrient supply rate was effective to compensate for effects of nutrient release as a result of soil sterilization in dune soil (Troelstra et al. 2001; van der Putten et al. 1988). The experiments were carried out in a greenhouse at a day temperature of $21^{\circ} \mathrm{C} \pm 2^{\circ} \mathrm{C}$ (day length $16 \mathrm{~h}$ ) with additional light (to maintain a minimum of $225 \mu \mathrm{mol} \mathrm{m}{ }^{-2} \mathrm{~s}^{-1}$ PAR with SON-T Agro lamps) and a night temperature of $16^{\circ} \mathrm{C}$. These temperatures are comparable with summer conditions in the field and are optimal for both plant and nematode development (Troelstra and Wagenaar unpublished results).

\section{Experiments}

\section{Experiment 1: multiplication of T. ventralis in sterilized} and nonsterilized dune soil

In this experiment, the effect of soil origin (mobile and stable dunes) and soil organisms on multiplication of the ectoparasitic nematode $T$. ventralis was tested. Half of the soil was sterilized by gamma irradiation at an average dose of $25 \mathrm{kGray}$, which eliminates microorganisms and nematodes effectively from dune soil (de Rooij van der Goes et al. 1998). One week after the seedlings of $A$. arenaria had been transplanted, half the pots were inoculated with $50 \mathrm{~T}$. ventralis pot $^{-1}$. The noninoculated pots served as controls for effects of $T$. ventralis on plant biomass production. There were six replicates of each treatment.

\section{Experiment 2: reproduction of $T$. ventralis in partially sterilized soil}

Multiplication of $T$. ventralis was studied in soils from which microarthropods and nematodes had been selectively removed by stirring the soil for $15 \mathrm{~min}$ at 1,500 rpm. This method has proven to effectively kill the soil fauna (de Rooij van der Goes et al. 1998). We confirmed this by inspecting the soil following stirring and found no live nematodes or microarthropods. The experiment was carried out as described above, but now the soil was completely sterilized by gamma irradiation (average $25 \mathrm{kGray}$ ), partially sterilized by stirring 
to remove the soil fauna, or nonstirred in order to have a nonsterilized control soil. Each soil was inoculated with 0,25 , or $250 T$. ventralis pot $^{-1}$ in order to examine any interaction between the effect of type of soil sterilization and nematode inoculation density. There were six replicates of each treatment.

\section{Experiment 3: reinoculation of microorganisms, nema- todes, and microarthropods into sterilized soil with $T$. ventralis}

In order to completely apply Koch's postulates, microarthropods, nematodes, and microorganisms were extracted from the soil of mobile and stable coastal foredunes and inoculated alone and in all factorial combinations into sterilized dune soil. Then, seedling plants of $A$. arenaria were grown as in the previous experiment, and every pot was inoculated with $50 \mathrm{~T}$. ventralis. All treatments were carried out in six replicates.

The microorganisms were obtained by shaking soil samples of $100 \mathrm{~g}$ with demineralized water $(1: 1 \mathrm{w} / \mathrm{w})$ for $10 \mathrm{~min}$ and filtering the supernatant through a 20$\mu \mathrm{m}$ mesh (Klironomos 2002). Prepared microbial filtrate contained no nematodes, but bacteria and fungi had readily passed through the filter. The pots with microorganisms were inoculated with $10 \mathrm{ml}$ of the filtrate, which was $1 / 15$ of the original soil density. For each pot, nematodes had been extracted from 1,500 $\mathrm{g}$ of nonsterile soil by Cobb's method (Oostenbrink 1960) and added in a suspension of $10 \mathrm{ml} \mathrm{pot}^{-1}$, so that nematode inoculation density corresponded with the density of nematodes in field soil. The nematode community added to the pots was analyzed microscopically (magnification $200 \times$ ) and consisted of plant parasites (T. ventralis, T. microphasmis, Pratylenchus spp, Paratylenchus spp., Meloidogyne spp., Rotylenchus spp., Criconematidae), bacterivores (Acrobeles spp., Acrobeloides spp., Chiloplacus spp., Cephalobidae, Plectus spp.), omnivores (Aporcelaimellus spp., Microdorylaimus spp.), and carnivores (Choanolaimus spp.).

Microarthropods were collected from nonsterile dune soil by wet sieving through $180-\mu \mathrm{m}$ mesh and added as $10 \mathrm{ml}$ of suspension pot ${ }^{-1}$, which corresponded with the field density of microarthropods. Demineralized water was added to all pots in equal amounts.

Assessing the presence of microbial enemies on nematodes in field soil

In order to confirm whether microbial enemies may occur on $T$. ventralis in the field, we extracted mobile nematodes from $100 \mathrm{~cm}^{3}$ of the field soil from each of the sampling sites using an adaptation of the Tray method (Whitehead and Hemming 1965). Half of the resulting nematode suspension was inspected using an inverted microscope (magnification 200x), and the nematodes were checked for symptoms of infection by bacteria or fungi. Nematodes infected by fungi were picked from the suspension and transferred to a cornmeal agar plate with antibiotics to encourage sporulation (Smith and Onions 1994), making possible identification of fungi that were previously found in a vegetative state. Identification of fungal natural enemies was done by observing mycelia and spore structure morphology and comparing this with the descriptions of Barron (1977). Endospores of the parasitic bacterium Pasteuria spp. were recorded when observed attached to the nematode cuticle. Symptoms of infection by a nonlethal bacterial parasite Microbacterium nematophilum were assessed according to Sulston and Hodgkin (1988).

To detect whether nematode natural enemies may occur as dormant forms in the soil, nematode-baited sprinkle plates were used. Soil $(1 \mathrm{~g})$ from each of the samples was sprinkled on water agar $(1 \%)$ in a $9-\mathrm{cm}-$ diameter Petri dish. A concentrated suspension of an estimated 500 Caenorhabditis elegans synchronized in the young adult stage (Sulston and Hodgkin 1988) was added to the plates. A negative control containing nematodes only in water agar $(1 \%)$ was used. The plates were sealed, kept at room temperature, and observed after 2 weeks and subsequently at weekly intervals up to 5 weeks (Barron 1977). Identification of fungal natural enemies was done as described above.

\section{Harvest}

All three experiments were harvested 12 weeks after inoculation of $T$. ventralis, allowing this nematode to complete two reproductive cycles (de Rooij van der Goes 1995). The nematodes were extracted from soil by Cobb's decantation method and from the roots using a mistifier (Oostenbrink 1960). The numbers of T. ventralis were counted using a microscope (magnification $200 \times$ ) and expressed as numbers $100 \mathrm{~g}^{-1}$ of dry soil. The roots and shoots of $A$. arenaria were dried for $48 \mathrm{~h}$ at $75^{\circ} \mathrm{C}$ and weighed.

\section{Data analysis}

Normal distribution of data and homogeneity of variance were checked by inspection of the residuals after model fit (using the package Statistica 7). To obtain the normal distribution of data and homogeneity of 
variances, numbers of $T$. ventralis were log transformed in experiment 1 and square-root transformed in experiment 2 . In all three experiments, the soil origin (stable or mobile dune) did not affect significantly $(P>0.05)$ the measured variables. Therefore, all data from treatments with those two soil origins was pooled, resulting in 12 replicates per treatment. Numbers of $T$. ventralis of experiment 1 were analyzed using one-way analysis of variance (ANOVA) with main the factor "soil treatment." Two-way ANOVA with the main factors "soil sterilization" and "nematode inoculation" were performed for root and shoot biomass. Three-way ANOVA with the main factors "stirring," "sterilization," and "inoculation density" were performed for analyzing the numbers of T. ventralis shoot and root biomass in experiment 2. Experiment 3 was analyzed by three-way ANOVA with the main factors "invertebrates," "nematodes," and "microorganisms." Treatments were compared by posthoc analysis using Tukey honestly significant difference (HSD) tests $(P<0.05)$.

\section{Results}

\section{Experiment 1}

The numbers of $T$. ventralis at harvest differed significantly between sterilized and nonsterilized soils $\left(F_{2,33}=77.9\right.$ and $\left.P<0.001\right)$. In the nonsterilized soil, addition of $T$. ventralis resulted in a significant increase of numbers at the end of the experiment compared with nonsterilized, noninoculated soil (Fig. 1). However, there were five times more $T$. ventralis in the inoculated sterilized soil than in the inoculated nonsterilized soil (Fig. 1; $P<0.05$; sterilized soil without $T$. ventralis added was not included because the nematodes were absent). These results show that multiplication of $T$. ventralis in nonsterilized soil was significantly enhanced by inoculation but that $T$. ventralis multiplication was significantly reduced by some factor in the nonsterilized soil that could be excluded by soil sterilization.

Soil sterilization influenced shoot biomass more than did T. ventralis inoculation $\left(F_{1,44}=117, P<0.001\right.$ for soil sterilization and $F_{1,44}=4.17, P<0.05$ for inoculation, Fig. 2), and the effect of $T$. ventralis inoculation depended on soil sterilization $\left(F_{1,44}=7.06, P<0.05\right)$. Most shoot biomass was produced in sterilized soil, whereas $T$. ventralis inoculation significantly reduced shoot biomass (Fig. 2). As expected, the least shoot biomass was produced in nonsterile soil; however, addition of $T$. ventralis caused no further reduction in

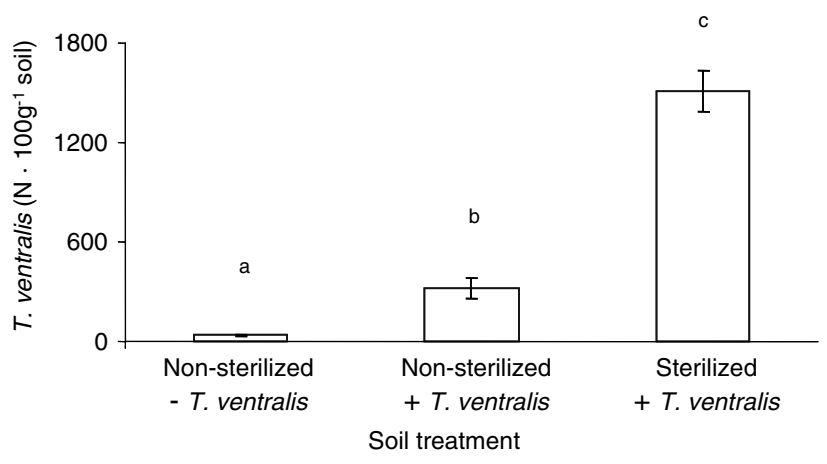

Fig. 1 Numbers of Tylenchorhynchus ventralis in $100 \mathrm{~g}$ of nonsterilized and sterilized dune soil 12 weeks after inoculation with T. ventralis. Error bars indicate standard error, and different letters above the bars indicate significant difference at $P<0.05$ (experiment 1 )
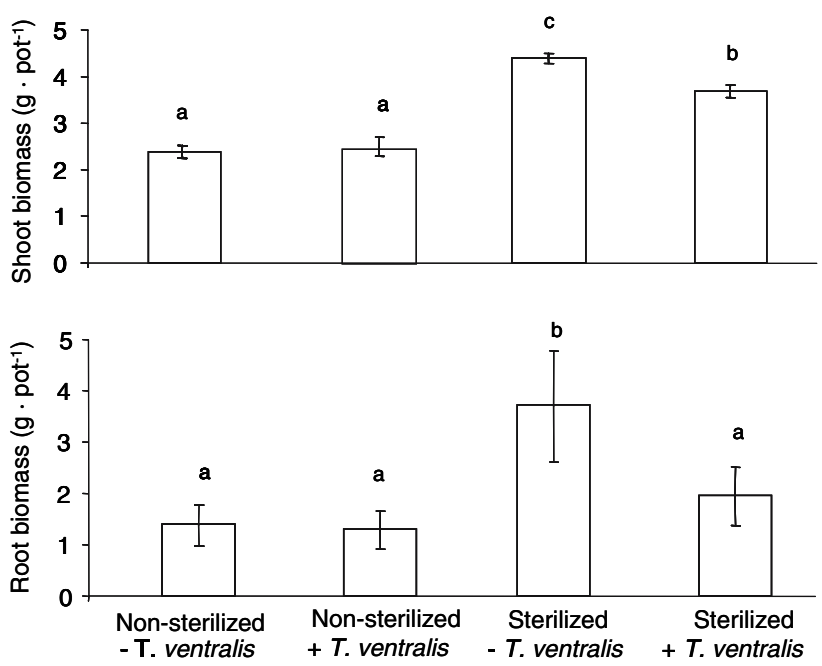

Fig. 2 Shoot and root biomass of Ammophila arenaria in sterilized and nonsterilized soil after 12 weeks from inoculation with Tylenchorhynchus ventralis. Error bars and letters above indicate significant differences at $P<0.05$ (experiment 1)

growth (Fig. 2). As expected, root biomass was also strongly influenced by soil sterilization $\left(F_{1,44}=56.1\right.$ and $P<0.001)$, whereas the effect of $T$. ventralis addition was greater than for shoot biomass $\left(F_{1,44}=16.8\right.$ and $P<0.001)$. As for shoot biomass, the effect of $T$. ventralis inoculation on root biomass depended on soil sterilization $\left(F_{1,44}=9.87\right.$ and $\left.P<0.005\right)$, which reflects that shoot biomass was significantly reduced by $T$. ventralis inoculation in the sterilized soil only (Fig. 2).

\section{Experiment 2}

Significantly greater populations of $T$. ventralis developed in sterilized than in nonsterlilized soil at both inoculation densities (Tables 1 and 2). At the low-inoculation density, the number of the nematodes in nonsterliized soil was 30 times less than in sterilized soil and 
Table 1 Three-way analysis of variance (ANOVA) of the numbers of Tylenchorhynchus ventralis in nonsterilized and sterilized, and stirred and nonstirred dune soil at three inoculation rates $\left(0,25,250\right.$ pot $\left.^{-1}\right)$ after 12 weeks from inoculation to Ammophila arenaria. The data has been square-root transformed to achieve normal error distribution

\begin{tabular}{lrcc}
\hline & $d f$ & $F$ & $P$ \\
\hline Stirring (1) & 1 & 3.481 & 0.06 \\
Sterilization (2) & 1 & 137.41 & $<0.001$ \\
Inoculation density (3) & 2 & 95.55 & $<0.001$ \\
$1 \times 2$ & 1 & 0.858 & 0.36 \\
$1 \times 3$ & 2 & 1.222 & 0.30 \\
$2 \times 3$ & 2 & 43.94 & $<0.001$ \\
$1 \times 2 \times 3$ & 2 & 1.499 & 0.23 \\
Error & 125 & & \\
\hline
\end{tabular}

Table 2 Effects of soil sterilization on numbers of Tylenchorhynchus ventralis in $100 \mathrm{~g}$ of soil $[ \pm 1$ standard error $(\mathrm{SE})] 12$ weeks from inoculation. Letters indicate significant differences at $P<0.05$ (experiment 2)

\begin{tabular}{lll}
\hline & Nonsterilized & Sterilized \\
\hline 0 T. ventralis added & $0.77 \pm 0.22^{\mathrm{a}}$ & $0.08 \pm 0.03^{\mathrm{a}}$ \\
25 T. ventralis added & $12.3 \pm 2.62^{\mathrm{b}}$ & $390 \pm 73.03^{\mathrm{c}}$ \\
250 T. ventralis added & $69.2 \pm 16.76^{\mathrm{b}, \mathrm{c}}$ & $1,162 \pm 203.7^{\mathrm{d}}$ \\
\hline
\end{tabular}

15 times less at the high-inoculation density. There was no significant effect of soil stirring on the numbers of $T$. ventralis, although there was a trend $(P=0.06)$ that stirring reduced $T$. ventralis multiplication.

As expected, both soil stirring and sterilization influenced shoot biomass (Fig. 3; Table 3). Shoot biomass was greater in sterilized than in nonsterilized soil and in stirred than in nonstirred soil; however, inoculation density of $T$. ventralis did not influence the shoot biomass (Fig. 3). Root biomass was affected by stirring,
Table 3 Shoot and root biomass of Ammophila arenaria 12 weeks after inoculation with nematodes

\begin{tabular}{lrcccc}
\hline & $d f$ & \multicolumn{2}{c}{ Shoot biomass } & \multicolumn{2}{c}{ Root biomass } \\
\cline { 2 - 6 } & & $F$ & $P$ & $F$ & $P$ \\
\hline Stirring (1) & 1 & 14.13 & $<0.001$ & 8.69 & $<0.01$ \\
Sterilization (2) & 1 & 30.49 & $<0.0001$ & 26.8 & $<0.001$ \\
Inoculation density (3) & 2 & 1.998 & 0.139 & 10.53 & $<0.001$ \\
$1 \times 2$ & 1 & 3.288 & 0.072 & 1.91 & 0.169 \\
$1 \times 3$ & 2 & 1.916 & 0.151 & 3.622 & $<0.05$ \\
$2 \times 3$ & 2 & 2.145 & 0.121 & 6.452 & $<0.01$ \\
$1 \times 2 \times 3$ & 2 & 1.921 & 0.151 & 1.911 & 0.152 \\
Error & 132 & & & & \\
\hline
\end{tabular}

The results of a factorial analysis of variance (ANOVA) with factors "stirring," "sterilization," and "inoculation density" (experiment 2)

soil sterilization, and inoculation density of $T$. ventralis, whereas effects of inoculation density depended on soil stirring as well as on soil sterilization (Table 3 ). If no nematodes were inoculated to the pots, soil sterilization almost doubled the root biomass. However, if inoculated with 25 or $250 \mathrm{~T}$. ventralis per pot, the roots in sterilized soil with $T$. ventralis did not produce more biomass than those in nonsterilized soil (Fig. 3). Root biomass was significantly increased by soil stirring when no or few $\left(25 \operatorname{pot}^{-1}\right) T$. ventralis were added to the pots, but there was no increase in root weight at the high inoculation rate.

\section{Experiment 3}

The multiplication of $T$. ventralis numbers was significantly reduced by adding a mixture of soil nematodes; however, the effect of adding microorganisms was far
Fig. 3 Effects of soil stirring, soil sterilization, and addition of Tylenchorhynchus ventralis on shoot and root biomass of Ammophila arenaria. Error bars and letters above indicate significant differences at $P<0.05$ (experiment 2)
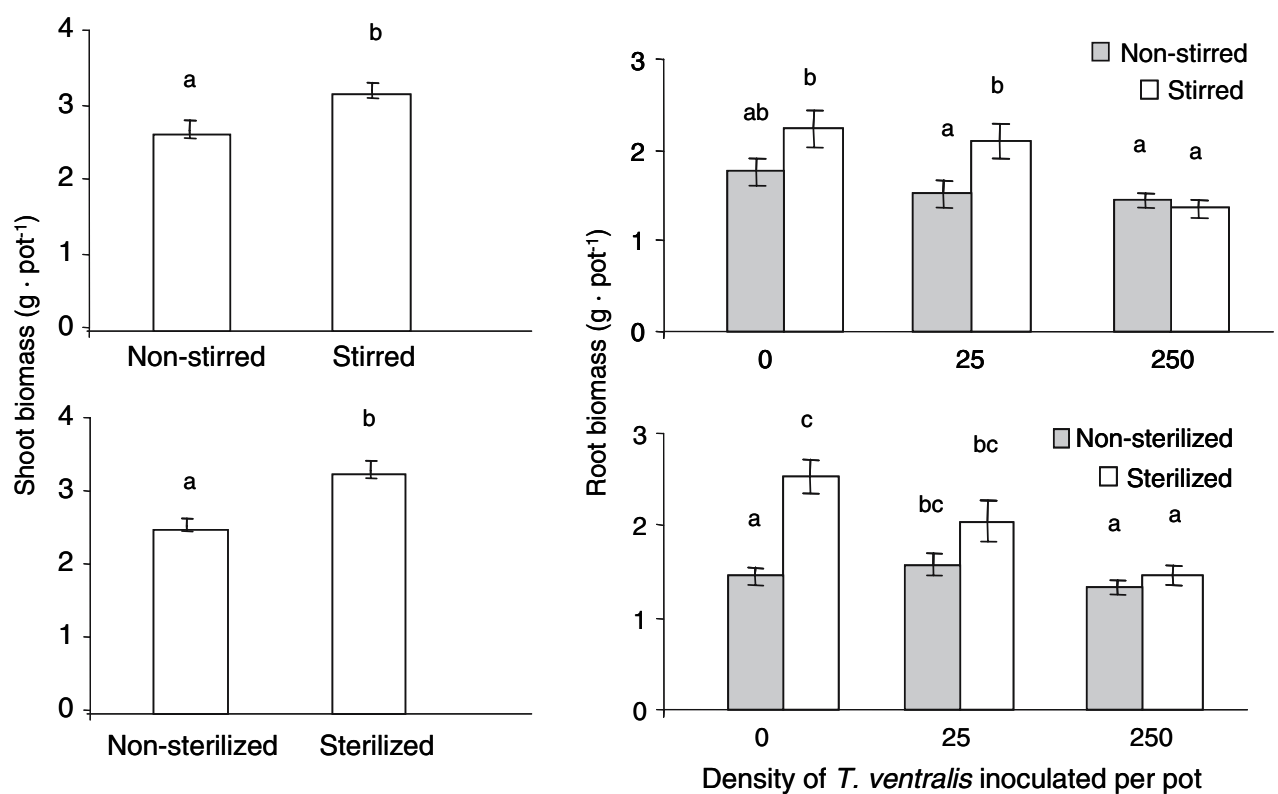
greater (Fig. 4; Table 4). If microorganisms were present alone or in combination with other soil organisms, the number of $T$. ventralis was always less than when microorganisms were absent. On average, adding a suspension of nematodes reduced final numbers of $T$. ventralis by $15 \%$, whereas adding microorganisms reduced numbers of $T$. ventralis by $55 \%$ (Fig. 4). Therefore, the effect of adding nematodes on $T$. ventralis multiplication was substantially weaker than the effect of microorganisms. Microarthropods did not have a significant effect on the numbers of $T$. ventralis. Adding microarthropods, nematodes, and microorganisms did not influence shoot or root biomass $(P>0.05$; data not shown).

In the suspension of nematodes obtained from the pots to which microorganisms had been added, $47.3 \%$ showed signs of infection by culturable microbial enemies (Table 5). The fungal parasite Catenaria spp. was found infecting 16 out of 110 T. ventralis inspected, and an unidentified fungus was detected inside 30 destroyed of 110 T. ventralis checked. Bacterial attachment to the cuticle was also observed for six nematodes, a Paenibacillus-like organism was found on four nematodes, and Pasteuria spp. on two out of 110 nematodes.

Assessing the presence of microbial enemies on nematodes in field soil

The fungal natural enemies Catenaria spp., Harposporium spp., and Myzocytium spp. were found infecting nematodes extracted by the Tray method (Whitehead and Hemming 1965). The bacterium $P$. penetrans was attached to root knot nematodes ( $M$. maritima). The fungal genera were also detected using nematodebaited sprinkle plates. Some of the nematodes on the plates had a swollen region behind the anus not observed in the original culture or in the negative control. This is a symptom of infection by a nonlethal bacterial parasite, M. nematophilum. An unidentified trapping fungus with nonconstricting rings was also
Table 4 The numbers of Tylenchorhynchus ventralis after 12 weeks from inoculation

\begin{tabular}{lccc}
\hline & $\begin{array}{l}\text { Degrees of } \\
\text { freedom }(d f)\end{array}$ & $F$ value & $P$ value \\
\hline Microarthropods (1) & 1 & 0.0006 & 0.981 \\
Nematodes (2) & 1 & 5.167 & $<0.05$ \\
Microorganisms (3) & 1 & 87.84 & $<0.0001$ \\
$1 \times 2$ & 1 & 1.736 & 0.191 \\
$1 \times 3$ & 1 & 0.618 & 0.434 \\
$2 \times 3$ & 1 & 0.672 & 0.415 \\
$1 \times 2 \times 3$ & 1 & 0.047 & 0.828 \\
Error & 88 & & \\
\hline
\end{tabular}

The results of a three-way analysis of variance (ANOVA) with factors "microarthropods," "nematodes," and "microorganisms" (experiment 3)

Table 5 Microbial enemies in or attached to Tylenchorhynchus ventralis in a suspension obtained from microorganism treatment pots in experiment 3

\begin{tabular}{ll}
\hline Microbial enemy detected & $\begin{array}{l}\text { Fraction of affected } \\
\text { nematodes }(\%)\end{array}$ \\
\hline Unidentified assimilative hyphae & 27.3 \\
Paenibacillus -like & 3.6 \\
Catenaria spp. & 14.5 \\
Pasteuria spp. & 1.8 \\
Total & 47.3 \\
(Healthy) & 52.7 \\
Total nematodes examined & $100(n=110)$
\end{tabular}

detected in the sprinkle plates but could not be identified, as it did not sporulate. These identifications may not have been exhaustive, but they confirmed the presence of antagonistic microorganism species on $T$. ventralis as well as in the soil from the field.

\section{Discussion}

In coastal foredunes, the root-feeding ectoparasitic nematode $T$. ventralis would significantly influence the pioneer grass $A$. arenaria if the density of this nematode was not controlled naturally. Our study strongly

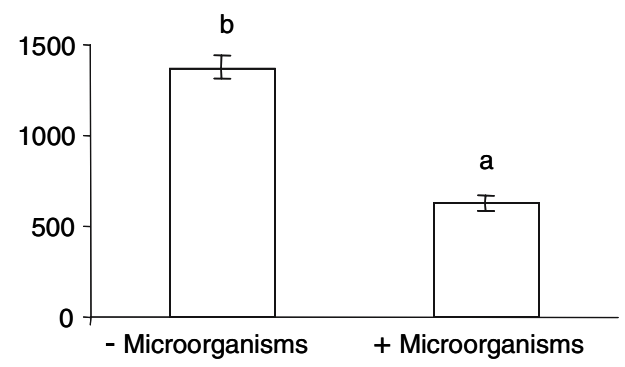

Fig. 4 The effects of mixed nematode inoculum and microorganisms on Tylenchorhynchus ventralis multiplication. Error bars and letters above indicate significant differences at $P<0.05$ (experiment 3 ) 
suggests that the natural control of $T$. ventralis in coastal foredune soil is mostly due to soil microorganisms. When inoculated into sterilized soil, numbers of $T$. ventralis were more than five times greater than when inoculated into nonsterilized soil, whereas selective elimination of soil fauna by stirring did not affect nematode numbers. These results from selective elimination studies were confirmed by isolating microarthropods, nematodes, and microbes and adding these together with $T$. ventralis to sterilized soil. Inoculation with soil microorganisms reduced $T$. ventralis more strongly than did inoculation with a nematode community consisting of other plant parasites, bacterivores, omnivores, and carnivores. The negative effect of the nematode community on $T$. ventralis density might have been due to competition with other root feeders. However, competition between $T$. ventralis and endoparasitic nematodes (i.e. H. arenaria, M. maritima and $P$. penetrans) occurred only if numbers of the competitors strongly exceeded present field densities (Brinkman et al. 2004). Therefore, the observed effect of adding nematodes on reducing $T$. ventralis was due to soil microorganisms cointroduced with the nematode suspension, carnivorous nematodes (Jairajpuri and Bilgrami 1990), or by effects of other non-plant-feeding nematodes. Our results highlight an important discrepancy in thinking about control mechanisms of plantfeeding (also called plant-parasitic) nematodes between biocontrol studies on the one hand and soil food web studies on the other. The majority of studies on the biocontrol of nematodes in agricultural ecosystems mostly focus on parasitic bacteria, such as $P$. penetrans and fungi (Kerry 2000), for example Arthrobotrys spp. and Pochonia spp. (Stirling and Smith 1998). Biological control practice usually does not consider microarthropods to be relevant for parasitic nematode control (Kerry and Gowen 1995), whereas the role of carnivorous nematodes has been considered (Mankau 1980; Yeates and Wardle 1996) but not successfully used. According to the food web model used by Neutel et al. (2002), root-feeding nematodes in coastal ecosystems are affected by predaceous mites and carnivorous nematodes. The role of microorganisms in nematode control is generally ignored in prominent soil food-web models (de Ruiter et al. 1993; Hunt et al. 1987). In our study system, however, soil microorganisms appeared to play a more important role than soil fauna in the control of plant ectoparasitic nematodes. In dune grasslands, the densities of soil fauna are usually rather low, perhaps too low to control significantly the abundance of nematodes (Petersen and Luxton 1982). Our results, therefore, support the view of biological control studies more than it supports soil food-web models for the control of the ectoparasitic nematode $T$. ventralis.

Our results suggest that top-down control by natural enemies is more important for ectoparasitic feeding generalists, such as $T$. ventralis, than are competition (Brinkman et al. 2004) or mycorrhizal fungi (Piśkiewicz and Hol unpublished results), although these control mechanisms have been suggested for the other endoparasitic root-feeding nematode species in the same study system (Brinkman et al. 2005; de la Peña et al. 2006; van der Stoel et al. 2006).

The control of $T$. ventralis in nonsterilized soil to which $T$. ventralis was added was not as good as in nonsterile soil, with only the background population of $T$. ventralis present. Earlier studies have shown that multiplication of $T$. ventralis is density and time dependent (de Rooij van der Goes 1995). Over time, a low inoculation density of nematodes may result in population increase, whereas a high inoculation density may result in population decline (de Rooij van der Goes 1995). However, we have no information as to how the microbial control shown in the present study may depend on nematode density, and subsequent long-term studies are required to further explore density dependence of nematode top-down control by microbes.

The two screening methods used to detect microbial enemies of nematodes in the soil yielded a diversity of fungal and bacterial antagonists. The Tray method (Whitehead and Hemming 1965) permitted the extraction of mobile stages of nematodes only, and therefore, dead or dying nematodes could not be screened. The nematode-baited sprinkle plate method, although useful for detecting microbial enemies in dormant forms in the soil, produced biased results that reflected the choice of nematode added, the bacterial-feeding nematode $C$. elegans. The fungal endoparasite Harposporium $\mathrm{spp}$. infects nematodes that ingest its spores and therefore would not be able to infect plant parasites due to the narrow lumen of the stylet (Barron 1977). The bacterium $M$. nematophilum is thought to be a specialist parasite of C. elegans (Hodgkin et al. 2000). $T$. ventralis was attacked by a subset of the microbial enemy genera found in the soil, which reflects some specificity in the action of these microbes. Some microorganisms, namely Pasteuria spp. and the Paenibacillus-like organism, have not been detected in the dune soil, although they are widespread in the dune sites. This may be due to their absence or to presence in small numbers that are below the level of detection. The unidentified assimilative hyphae could be the result of attack by generalist trapping fungi. This was a first assessment to confirm the presence of nematode antagonistic microorganisms on $T$. ventralis, and 
further studies are needed to isolate culture and inoculate those antagonists in order to evaluate their contribution in root-feeding nematode control.

Soil sterilization always led to increased root and shoot biomass. Previous studies have already shown that soil biota may reduce performance of $A$. arenaria (van der Putten et al. 1988; van der Stoel et al. 2002). The effect of soil sterilization was greater for root biomass than for shoot biomass. In sterilized soil, enhanced plant growth can be caused by nutrient release as a result of the soil sterilization process (Troelstra et al. 2001). We avoided different nutrient status of the sterilized and nonsterilized treatments by adding nutrient solution (van der Putten et al. 1988). When added to sterilized soil, the root-feeding nematode $T$. ventralis reduced root and shoot biomass of $A$. arenaria, and the effect of nematodes on root biomass increased with increasing inoculation density. Addition of $T$. ventralis to the nonsterile soil did not change root biomass, showing that the contribution of this nematode species to growth reduction of $A$. arenaria is limited (de Rooij van der Goes 1995). Our study shows that the dune soil not only contains biotic factors that reduce growth of $A$. arenaria but that there are also (micro) organisms that control population abundance of $T$. ventralis. In prairie grassland ecosystems, root-feeding nematodes have been assessed to account for reducing $58 \%$ of aboveground biomass (Stanton 1988). These estimates are based on elimination trials using soil biocides. However, these studies did not verify the biocide effects by inoculation trials, and they also did not account for natural top-down control of the root-feeding nematodes. Our results suggest that when assessing the effects of root feeders on plant production, interactions of the root feeders with their natural predators needs to be taken into account as well.

We conclude that soil microorganisms contribute to controlling the plant ectoparasitic nematode $T$. ventralis at a low population density in natural coastal foredunes. When not controlled, T. ventralis would be a key control factor for $A$. arenaria performance. Addition of other soil fauna, i.e., nematodes and microarthropods, did not influence the abundance of T. ventralis as much as microorganism addition did, which confirms the marginal effects of soil fauna removal on reproduction of $T$. ventralis. Our results suggest that belowground multitrophic interactions can be crucial for plant performance. Revealing the precise identity of the microorganisms that have negative effects on the $T$. ventralis population, as well as mechanisms and involvement of the host plant, need further studies.
Acknowledgments This study is part of the EcoTrain project (HPRN-CT 2002 00210), which is funded by the European Union.

\section{References}

Barron GL (1977) The nematode destroying fungi. Canadian Publications, Ontario

Bezemer TM, van Dam NM (2005) Linking aboveground and belowground interactions via induced plant defenses. Trends Ecol Evol 20:617-624

Bezemer TM, de Deyn GB, Bossinga TM, van Dam NM, Harvey JA, van der Putten WH (2005) Soil community composition drives aboveground plant-herbivore-parasitoid interactions. Ecol Lett 8:652-661

Brinkman EP, van Veen JA, van der Putten WH (2004) Endoparasitic nematodes reduce multiplication of ectoparasitic nematodes, but do not prevent growth reduction of Ammophila arenaria (L.) Link (marram grass). Appl Soil Ecol 27:65-75

Brinkman EP, Duyts H, van der Putten WH (2005) Consequences of variation in species diversity in a community of root-feeding herbivores for nematode dynamics and host plant biomass. Oikos 110:417-427

Brown VK, Gange AC (1990) Insect herbivory below ground. Adv Ecol Res 20:1-58

Carson WP, Root RB (1999) Top-down effects of insect herbivores during early succession: influence on biomass and plant dominance. Oecologia 121:260-272

Davis RF, Noel GR, Wilkinson HT (1994) Pathogenicity of Tylenchorhynchus nudus to creeping bentgrass and annual bluegrass. Plant Dis 78:169-173

de Deyn GB, Raaijmakers CE, Zoomer HR, Berg MP, de Ruiter PC, Verhoef HA, Bezemer TM, van der Putten WH (2003) Soil invertebrate fauna enhances grassland succession and diversity. Nature 422:711-713

de Deyn GB, Raaijmakers CE, van Ruijven J, Berendse F, van der Putten WH (2004) Plant species identity and diversity effects on different trophic levels of nematodes in the soil food web. Oikos 106:576-586

de la Peña E, Echeverria SR, van der Putten WH, Freitas H, Moens M (2006) Mechanism of control of root-feeding nematodes by mycorrhizal fungi in the dune grass Ammophila arenaria. New Phytol 169:829-840

de Rooij van der Goes PCEM (1995) The role of plant parasitic nematodes and soil borne fungi in the decline of Ammophila arenaria (L) Link. New Phytol 129:661-669

de Rooij van der Goes PCEM, van der Putten WH, van Dijk C (1995) Analysis of nematodes and soil borne fungi from Ammophila arenaria (Marram grass) in Dutch coastal foredunes by multivariate techniques. Eur J Plant Pathol 101:149-162

de Rooij van der Goes PCEM, Peters BAM, van der Putten WH (1998) Vertical migration of nematodes and soil-borne fungi to developing roots of Ammophila arenaria (L.) Link after sand accretion. Appl Soil Ecol 10:1-10

de Ruiter PC, van Veen JA, Moore JC, Brussaard L, Hunt HW (1993) Calculation of nitrogen mineralization in soil food webs. Plant Soil 157:263-273

Eisenback JD (1993) Interactions between nematodes in cohabitance. In: Khan MW (ed) Nematode interactions. Chapman \& Hall, London, pp 134-174

Hodgkin J, Kuwabara PE, Corneliussen B (2000) A novel bacterial pathogen, Microbacterium nematophilum, induces morphological change in the nematode $C$. elegans. Curr Biol 10:1615-1618 
Hol WHG, Cook R (2005) An overview of arbuscular mycorrhizal fungi-nematode interactions. Basic Appl Ecol 6:489-503

Hunt HW, Coleman DC, Ingham ER, Ingham RE, Elliott ET, Moore JC, Rose SL, Reid CPP, Morley CR (1987) The detrital food web in a shortgrass prairie. Biol Fertil Soils 3:57-68

Ingham RE, Detling JK (1986) Nematode population dynamics from different aged prairie dog colonies. J Nematol 18:638638

Jairajpuri MS, Bilgrami AL (1990) Predatory nematodes. In: Jairajpuri MS, Alam MM, Ahmad I (eds) Nematode bio-control: aspects and prospects. CBS Publishers, New Delhi

Kerry BR (2000) Rhizosphere interactions and the exploitation of microbial agents for the biological control of plant parasitic nematodes. Annu Rev Phytopatol 38:423-441

Kerry BR, Gowen SR (1995) Biological control of plant parasitic nematodes. Nematologica 41:362-363

Klironomos JN (2002) Feedback with soil biota contributes to plant rarity and invasiveness in communities. Nature 417:67-70

Mankau R (1980) Biological control of nematode pests by natural enemies. Annu Rev Phytopatol 18:415-440

Neutel AM, Heesterbeek JAP, de Ruiter PC (2002) Stability in real food webs: weak links in long loops. Science 296:1120 1123

Oostenbrink M (1960) Estimating nematode populations by some selected methods. In: Sasser JN, Jenkins WR (eds) Nematology. The University of North Carolina Press, Chapel Hill, pp 85-102

Petersen H, Luxton M (1982) A comparative analysis of soil fauna populations and their role in decomposition processes. Oikos 39:287-388

Polis GA, Strong DR (1996) Food web complexity and community dynamics. Am Nat 147:813-846

Rasmann S, Kollner TG, Degenhardt J, Hiltpold I, Toepfer S, Kuhlmann U, Gershenzon J, Turlings TCJ (2005) Recruitment of entomopathogenic nematodes by insect-damaged maize roots. Nature 434:732-737

Rosenheim JA (1998) Higher order predators and the regulation of insect herbivore populations. Annu Rev Entomol 43:421-447

Schmitz OJ, Krivan V, Ovadia O (2004) Trophic cascades: the primacy of trait-mediated indirect interactions. Ecol Lett 7:153-163

Sikora RA (1992) Management of the antagonistic potential in agricultural ecosystems for the biological control of plant parasitic nematodes. Annu Rev Phytopatol 30:245-270

Smith D, Onions AHS (1994) The preservation and maintenance of living fungi. CAB International, Wallingford

Stanton NL (1988) The underground in grasslands. Annu Rev Ecol Syst 19:573-589

Stirling GR, Smith LJ (1998) Field tests of formulated products containing either Verticillium chlamydosporium or Arthro- botrys dactyloides for biological control of root-knot nematodes. Biol Control 11:231-239

Strong DR, Kaya HK, Whipple AV, Child AL, Kraig S, Bondonno M, Dyer K, Maron JL (1996) Entomopathogenic nematodes: natural enemies of root-feeding caterpillars on bush lupine. Oecologia 108:167-173

Strong DR, Whipple AV, Child AL, Dennis B (1999) Model selection for a subterranean trophic cascade: root-feeding caterpillars and entomopathogenic nematodes. Ecology 80:2750-2761

Sulston J, Hodgkin J (1988) Methods. In: Wood WB (ed) The nematode Caenorhabditis elegans. Cold Spring Harbor Laboratory Press, Cold Spring Harbor, pp 587-606

Troelstra SR, Wagenaar R, Smant W, Peters BAM (2001) Interpretation of bioassays in the study of interactions between soil organisms and plants: involvement of nutrient factors. New Phytol 150:697-706

van der Putten WH (2003) Plant defense belowground and spatiotemporal processes in natural vegetation. Ecology 84:2269-2280

van der Putten WH, van Dijk C, Troelstra SR (1988) Biotic soil factors affecting the growth and development of Ammophila arenaria. Oecologia 76:313-320

van der Stoel CD, van der Putten WH, Duyts H (2002) Development of a negative plant-soil feedback in the expansion zone of the clonal grass Ammophila arenaria following root formation and nematode colonization. J Ecol 90:978-988

van der Stoel CD, Duyts H, van der Putten WH (2006) Population dynamics of a host-specific root-feeding cyst nematode and resource quantity in the root zone of a clonal grass. Oikos 112:651-659

Verschoor BC, de Goede RGM, Brussaard L (2002) Do plant parasitic nematodes have differential effects on the productivity of a fast- and a slow-growing grass species? Plant Soil 243:81-90

Walker M, Jones TH (2001) Relative roles of top-down and bottom-up forces in terrestrial tritrophic plant-insect herbivorenatural enemy systems. Oikos 93:177-187

Whitehead AG, Hemming JR (1965) A comparison of some quantitative methods of extracting small vermiform nematodes from soil. Ann Appl Biol 55:25-38

Yeates GW (1987) How plants affect nematodes. Adv Ecol Res 17:61-113

Yeates GW, Wardle DA (1996) Nematodes as predators and prey: relationships to biological control and soil processes. Pedobiologia 40:43-50

Yeates GW, Bongers T, de Goede RGM, Freckman DW, Georgieva SS (1993) Feeding habits in soil nematode families and genera-an outline for soil ecologists. J Nematol 25:315-331 